\title{
Legitimidade da metáfora em língua de especialidade num quadro didáctico
}

Isabelle Oliveira*

RESUMO: O escopo deste trabalho é propor uma reflexão e um contributo acerca da metáfora em língua de especialidade, ou seja, um tipo de metáfora que facilita, num contexto de aprendizagem, a transmissão dos conhecimentos, a compreensão do abstracto ao tecer analogias com o concreto ou o familiar. Com este propósito, ver-se-á como o docente, na área da cardiologia, tenta transmitir a sua mensagem através da utilização de uma imagem comum à vida quotidiana dos estudantes. Deste facto, vamos colocar a metáfora terminológica num contexto hermenêutico que supõe outra forma de pensar e outro modo de ver o objecto de descrição. Temos de sublinhar que, nesta perspectiva, a metáfora opera uma re-descrição da realidade. O docente tem ao seu dispor um termo altamente científico ou uma expressão metafórica para designar um mesmo objecto. A partir de alguns exemplos vamos verificar que o instrumento metafórico funciona como um tradutor intralingual que assume essencialmente a função de ilustrador. A metáfora de especialidade com carácter explicativo resulta de uma preocupação de clareza pedagógica e visa uma eficácia na compreensão de conceitos abstractos. Para finalizar, focar-se-á as principais potencialidades e entraves que podemos atribuir à metáfora numa situação de aprendizagem.

PALAVRAS-CHAVE: Metáfora terminológica; metalinguagem; aprendizagem; estratificação social.

\section{Introdução}

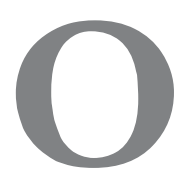

s estudos sobre a metáfora têm despertado o interesse não apenas de áreas a ela tradicionalmente ligadas, como a literatura, mas também de áreas diversas do conhecimento, nomeadamente a Linguística, a Filosofia, a Antropologia Cultural, as Ciências Cognitivas, a Didáctica, entre outras. Assim, ao longo dos séculos, e principalmente nos nossos dias, teorias, experiências e estudos aplicados envolvendo a

\footnotetext{
* Université Paris 3-Sorbonne Nouvelle, França - Isabelle.Oliveira@isc.cnrs.fr.
} 
metáfora não cessaram de se multiplicarem, de tal modo que podemos falar de uma autêntica "indústria" do produto metafórico. Em relação à língua portuguesa, porém, este estado de industrialização não parece ainda ter chegado. Os estudos sobre a linguagem metafórica não abundam e os que existem centram-se, na grande maioria das vezes, na sua utilização em textos literários. Nenhum estudo se interessou suficientemente de perto à análise da metáfora em língua de especialidade num quadro didáctico. Acreditamos que a metáfora é uma necessidade em ciência, um instrumento valioso que carece de uma utilização específica. É certo que durante muito tempo, esta visão da metáfora não tivera adesão uma vez que esta contrariava a tradição Wüsteriana que a considerava uma entidade não racional tendente às representações vagas e de tipo subjectivo, desprovidas de rigor científico e, portanto, portadoras de ambiguidade. A nossa leitura é outra. A metáfora é uma via frequentemente utilizada pelos cientistas que podem testar a sua eficácia em denominar e em produzir conhecimento. Constatou-se, ainda, que a metáfora terminológica desempenha um papel fulcral na comunicação especializada o que, durante muito tempo, nos foi negado. Todavia, deparamo-nos com algumas interrogações: o que é uma metáfora terminológica? O que é compreender uma metáfora terminológica? Que conhecimentos do Mundo são necessários para a análise de metáfora de especialidade?... Algumas das questões que analisaremos de seguida.

\section{Definição da metáfora terminológica}

A dimensão metafórica constitui um vasto campo de investigação em que várias disciplinas podem partilhar a exploração deste universo. Todavia, na nossa análise, vamo-nos interrogar sobre o estatuto da metáfora terminológica, um tema de reflexão ainda pouco desenvolvido. De facto, este tipo de metáfora inscreve-se dentro da língua de especialidade e obedece a um modo operatório peculiar. Considera-se indesejável o uso de metáforas nos discursos científicos ou técnicos, vistas exclusivamente como simples jogos da linguagem que serviam a criar efeitos estéticos agradáveis, quando observadas a partir da visão aristotélica de ornamento na poética e de persuasão na retórica. Pensamos que ao reduzir a metáfora a um ornamento da linguagem se dissimula um temor de uma metáfora não racional, metáfora considerada subjectiva e privada de rigor científico. Estabelecido o enquadre teórico, passaremos à questão específica da metáfora terminológica presente nos discursos da cardiologia. Assim, Assal já pavimentou o caminho ao contribuir com reflexões para o desenvolvimento desse novo olhar sobre a metáfora de especialidade: 
La métaphore terminologique est loin d'être une simple façon de parler, elle est essentiellement une manière de penser. Certes elle est un emprunt imagé, mais une fois que cet emprunt est réinvesti dans une pratique sociale, une fois que sa signification est réglée par les acteurs agissant dans le cadre de cette pratique, elle devient l'expression d'un nouveau concept. (Assal, 1994, p. 23)

Chegamos, deste modo, à visão da metáfora que é objecto deste trabalho. Longe de ser um mero ornamento da linguagem, ela é uma operação cognitiva essencial para a nossa compreensão do mundo. Iremos mais longe apresentando a metáfora terminológica como uma chave linguística nas conceptualizações cognitivas da aprendizagem. Parece-nos bastante clara aqui a consciência de que a metáfora terminológica não constitui, de forma alguma, um conjunto caótico e desorganizado, mas segue uma ordem determinada que deve guiar o estudante enquanto estrutura conceptualmente nova do domínio de estudo. Mais do que isso, trata-se de uma metáfora estrutural que organiza as representações e as experiências através de denominações simples ou complexas lexicalizadas que se propagam no tempo e no espaço e que tem uma suposta existência para a comunidade linguística. Da mesma forma, a unidade terminológica metafórica deve inscrever-se num quadro convencional preciso já que é governada por um conjunto de esquemas conceptuais que não pode infringir. Deixamos aqui anotado que se trata de uma metáfora familiar, recorrente, transparente, que não exige nenhum trabalho intelectual especial de interpretação, nenhum esforço particular de inferência porque o seu carácter de tropo não deve escapar à consciência do estudante a fim de evitar qualquer confusão possível. Assim, quando a metáfora entra oficialmente nas práticas da sala de aulas de iniciação de uma disciplina, começa-se por falar da metáfora terminológica, torna-se um instrumento de manipulação e de aplicação que dá sentido às experiências sensoriais tanto dos professores como dos alunos. Após uma aprovação unânime, descobrimos uma metáfora terminológica totalmente lexicalizada, convencional, imperceptível, aprovada socialmente, reconhecida como pertinente para a comunidade científica veiculando um sentido literal ao mesmo título que o termo altamente científico. É de realçar que este tipo de metáfora aspira a um ideal de intelectualização, a uma sistematização conceptual e a uma neutralidade emotiva.

Por último, na nossa análise, podemos entender a metáfora a partir de duas vertentes principais: a metáfora terminológica (estrutura os sistemas conceptuais a partir do que compreendemos do mundo e da forma como agimos nele), que seria aquela que se materializa verbalmente pelo enunciado de uma língua de especialidade, e a metáfora conceptual, aquela que é estruturada no pensamento humano (Lakoff e Johnson, 1985). Podemos concluir que, 
apesar dos dois usos, cognitivo e linguístico da metáfora, trata-se afinal da mesma faculdade e do mesmo poder mediador entre o inteligível e o sensível.

\section{Da utilidade da metáfora como instrumento de re-descrição da realidade}

Num contexto de aprendizagem, podemos questionar-nos sobre a razão pela qual o docente prefere exprimir-se de forma metafórica quando podia simplesmente recorrer ao termo altamente científico. Nesse mesmo sentido, será que essa escolha optativa em substituir um termo metafórico por outro termo científico traduz uma preocupação estética? Assim, será que a metáfora só possui um valor ornamental? Não é possível encarar aqui outra função da metáfora? É óbvio que a metáfora terminológica não se limita a desempenhar um modesto papel subalterno de acompanhamento, de complemento ou ainda uma simples máscara ornamental do discurso. Nesta óptica, a função fulcral da metáfora de especialidade consiste em criar uma metalinguagem que permite trazer um novo olhar sobre o objecto observado. No âmbito da fenomenologia hermenêutica, o emprego da metáfora terminológica implica uma outra maneira de pensar e de ver o objecto de descrição. Aqui a metáfora abre novos horizontes de percepção alargando o campo da experiência. Esta modifica o nosso conhecimento do mundo e permite descobrir um ou mais aspectos da realidade. Lembramos que a metáfora é vista como uma analogia condensada por fusão de um elemento do foro com um elemento do tema. A metáfora torna-se, assim, um conceito, um "design", uma forma diferente de traduzir a realidade ou uma experiência. Como referem Lakoff e Johnson, a essência da metáfora assenta numa transferência de experiências:

L'essence d'une métaphore est qu'elle permet de comprendre quelque chose (et d'en faire l'expérience) en terme de quelque chose d'autre. (Lakoff e Johnson, 1985, p. 15)

De facto, o modo operatório da metáfora consiste em transportar de um local para o outro diferentes aspectos do pensamento para se tornar uma metalinguagem, um novo modo de representação, a expressão alternativa de uma experiência vivida. A metáfora não trai a realidade, mas redescreve-a em termos novos, sem por isso deixar de permanecer verdadeira. É interessante realçar o impacto metafórico no domínio de aplicação da cardiologia porque permite simplificar noções complexas dispondo de um potencial imaginado e evocativo forte dentro da representação dos conceitos.

A função da imaginação é esquematizar a atribuição do metafórico no vislumbrar de relações incongruentes e de semelhança a partir de uma diver- 
sidade de experiências passadas ou presentes. A metáfora estrutura uma visão de mudança do objecto de descrição e permite um exame dos seus elementos peculiares. Ela pensa o mundo diferentemente e permite a compreensão de elementos que podem escapar ao entendimento racional.

\section{Escolha de um candidato suplente}

Por vezes, na nossa análise, verificamos que um candidato metafórico se apresenta preparado para o papel de substituto terminológico.

Notou-se que a metáfora terminologica é convidada, numa situação de aprendizagem, a desempenhar um papel de substituição. O objectivo da metáfora num quadro de substituição é de favorecer a compreensão de um ou mais aspectos do conceito que ela estrutura. Neste caso, o professor reencontra neste modelo substitutivo dois caminhos distintos na forma de denominar onde pode testar a validade heurística. Com efeito, este processo distingue-se pela presença de pelo menos duas formas para um mesmo conceito. Assim, o docente tem ao seu dispor dois tipos de termos diferentes em que o diálogo pode ser instaurado com os estudantes podendo, deste modo, as diferenças de nível serem ultrapassadas.

Desde já, podemos citar vários exemplos do domínio da cardiologia para nos aperceber melhor deste fenómeno de dupla denominação aquando da designação de um mesmo objecto:

Hypertrofia ventricular direita

- Coração em tamanco/coração em gota de vinho

A metáfora "coração em tamanco" recorre à memória visual introduzindo um aspecto lúdico, ela é muito menos rebarbativa do que um termo altamente científico como "hypertrofia ventricular direita". Neste caso, tratase de uma construção analógica explicativa que compensa as lacunas da linguagem científica, que, em certas situações de comunicação, não torna o conceito suficientemente palpável.

Numa estratégia de aprendizagem, o docente pode sem problema algum substituir o termo científico pelo seu equivalente metafórico. Noutros termos, a metáfora terminológica torna-se, portanto, o equivalente de uma noção existente que adopta uma denominação com a qual se relaciona. Ela implica sobretudo uma estratégia conversacional em função do objectivo comunicativo e o seu papel num contexto de re-descrição consiste em aclarar um concei- 
74 OLIVEIRA, Isabelle. Legitimidade da metáfora em língua de especialidade num quadro didáctico

to pouco familiar associando-o a um conceito mais transparente para nós e nunca o contrário. Assim, o professor recorre a uma metalinguagem para explicar termos herméticos do domínio da cardiologia.

Os exemplos seguintes testemunham nitidamente da existência em cardiologia de uma proliferação de metáforas terminológicas que substituem o termo altamente científico:

- Pseudocoartação da aorta - Aorta pregueada

- Hypertrofia ventricular direita - Coração em tamanco/ Coração em gota de vinho

- Angor de Prinzmental - Enfarte de repouso

- Pulso de Corrigan - Pulso saltão/ Pulso em martelo de água

- Angiocardiosclerose - Coração senil

- Síncope da tosse - Ictus laríngeo/Engorgitamento venoso

- Hipoplasia do ventrículo direito - Ventrículo papiráceo

- Enfarte isquémico - Enfarte branco

- Embriocardia dissociada - Ritmo pendular

Verifica-se aqui uma necessidade em recorrer às potencialidades da metáfora para descrever as realidades observadas dado que a linguagem científica, às vezes, dificulta o entendimento de alguns aspectos desta mesma realidade. Sob esta perspectiva, o objectivo da metáfora consiste em provocar uma melhor compreensão de um aspecto do conceito que ela estrutura, por sobreposição do termo metafórico e do termo altamente científico permitindo uma compreensão mútua dos diferentes aspectos do conceito. Esta mudança de paradigmas científicos traz forçosamente uma modificação da percepção da realidade em que a metáfora vem enriquecer o nosso conhecimento do mundo. Para reforçar o nosso propósito, exemplifiquemos com "aorta a cavalo", que remete para "dextroposição da aorta": é natural que o aprendente por meio da locução "a cavalo" visualize perfeitamente a posição da aorta e apreenda o problema, ao passo que o termo "dextroposição da aorta" tornase menos acessível para ele.

Fontanier já sublinhava que a metáfora consistia em:

Présenter une idée sous le signe d'une autre idée plus frappante ou plus connue, qui, d'ailleurs, ne tient à la première par aucun lien que celui d'une conformité ou analogie. (Fontanier, 1968, p. 44) 
Deduzimos que o instrumento metafórico pode ilustrar os conhecimentos dos estudantes tornando-os mais atraentes e acessíveis.

Cícero chegou a enunciar algumas regras para uma boa utilização do instrumento metafórico:

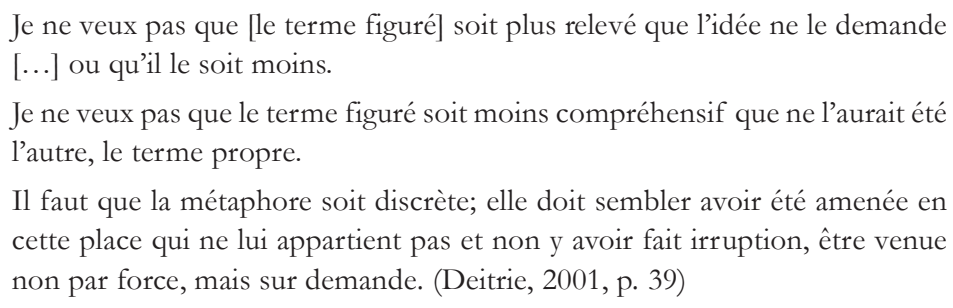

Il faut que la métaphore soit discrète; elle doit sembler avoir été amenée en cette place qui ne lui appartient pas et non y avoir fait irruption, être venue non par force, mais sur demande. (Deitrie, 2001, p. 39)

Todas estas recomendações de Cícero parece-nos pertinentes para um bom funcionamento da metáfora numa estratégia de aprendizagem. É verdade que a metáfora torna possível conceber e apreender o mundo de forma diferente e contribui para aumentar as capacidades cognitivas do estudante. Compreendemos qual o motivo de, numa primeira fase de aprendizagem, a metáfora figurar nas aulas de iniciação do domínio. Eis a razão pela qual a metáfora se apropria do lugar do termo científico que desaparece.

Ela substitui o termo científico quando tem mais impacto do que este nas interacções professor-alunos. A título de exemplo, a metáfora "clave de sol", interpela mais a imaginação, visualiza, especifica e enfeita o discurso do especialista tornando-o mais acessível. Num âmbito de aprendizagem, o instrumento metafórico torna-se para o docente um acessório circunstanciado que pinta os objectos com mais energia do que o termo altamente científico. Por exemplo, com a metáfora "coração de leão" e "novacor", observamos que a metáfora é muito mais eloquente, elucidativa, reveladora do que o termo altamente científico que não revela nenhuma informação sobre as propriedades deste semicoração artificial a não ser a sua novidade. $O$ termo metafórico "coração de leão" possui dois elementos de nominação em que o elemento "coração" se relaciona com o conceito "novacor". Os traços conceptuais "potência", "energia", "vigor" são deduzíveis a partir dos conhecimentos enciclopédicos dos enunciadores sobre o conceito "leão". Esta metáfora é um exemplo típico da sua capacidade a produzir e veicular conhecimento e surge como um instrumento imprescindível para a comunicação humana na construção do nosso pensamento. 
76 OLIVEIRA, Isabelle. Lesitimidade da metáfora em língua de especialidade num quadro didáctico

\section{A metáfora: um instrumento ao serviço do ensino}

Em certas circunstâncias de comunicação, o instrumento metafórico pode atingir um nível de compreensão muito mais profundo do que o termo científico, pois indica um processo de aprendizagem e de descoberta. Todavia, fica ainda uma questão: na verdade, será que estas metáforas têm a riqueza conceptual necessária para traduzir a complexidade destas noções? É provável que as metáforas mais elucidativas, mais acessíveis, possam ser desprovidas da riqueza conceptual esperada para representar a complexidade conceptual do termo científico.

Contudo, não devemos nos deixar seduzir pela metáfora e fazer dela a nossa pedra angular porque, por vezes, verificamos uma perda cognitiva significativa nesta última. Para exemplificar, citemos o termo "tetralogia de Fallot", sinónimo de "doença azul": na análise do termo científico "tetralogia de Fallot" apercebemo-nos graças ao formante "tetra" que "tetralogia" referencia quatro anomalias do coração (uma falha da comunicação inter-ventricular, falha da comunicação inter-auricular e uma anomalia da artéria pulmonar). Pelo contrário, o termo metafórico "doença azul" remete somente para uma descrição do paciente que apresenta uma cor azulada. Neste exemplo, observamos nitidamente uma perda cognitiva na metáfora muito mais afastada da realidade. Aqui não se trata de proscrever a analogia da ciência, mas tentarmos explicar por quê algumas analogias são mais eficazes do que outras. Para finalizar, vamos destacar algumas potencialidades e desvantagens específicas à metáfora terminológica num contexto de aprendizagem.

Deixamos aqui anotado alguns benefícios do recurso à metáfora de especialidade num processo de aprendizagem:

> Abre novas perspectivas e autoriza mudanças no plano conceptual;

> Facilita a compreensão do abstracto ao apontar similitudes no mundo real;

$>$ Permite uma certa visualização dos conceitos abstractos e convida-nos a olhar para o mundo sob um ângulo diferente;

$>$ Obriga o professor a levar em consideração as concepções prévias do aprendente.

Por outro lado, a metáfora de especialidade apresenta algumas desvantagens na sua utilização: 
$>$ Parte-se do pressuposto que uma metáfora construída numa conexão semântica incongruente ou inadequada não poderá fazer surgir a imagem desejada, o seu lugar analógico visado. Se não conseguirmos identificar o modo de relação entre o domínio-fonte e o domínio-alvo, a metáfora permanecerá imprecisa. Se a utilização de metáforas precisas contribui para a qualidade da análise dos problemas, o recurso a metáforas inadequadas torna-se um autêntico labirinto armadilhado;

$>$ Uma metáfora nunca assenta numa similaridade total entre o domíniofonte e o domínio-alvo. As diferenças criadas podem, agora, induziremse sobre as concepções erradas;

$>$ O recurso ao raciocínio analógico numa situação de aprendizagem deve seguir sempre uma orientação. Frequentemente, o docente contenta-se em evocar a analogia sem se preocupar em trazer uma explicação pois acredita que a sua compreensão é evidente para o estudante que se encontra numa fase de descoberta de novos conceitos;

$>$ O raciocínio analógico é possível somente se as comparações forem elaboradas pelos próprios aprendentes. Logo à partida, se o estudante tiver concepções erradas do domínio-fonte, ele vai transpô-las para o domínio-alvo por meio da analogia, o que dificulta a compreensão do termo metafórico.

\section{Um problema de tradução ligado ao caso específico da metáfora auditiva}

Sucede que, tanto os especialistas franceses como portugueses e ingleses não denominam e não descrevem alguns ruídos de forma idêntica, o que avivou a nossa curiosidade. Repara-se por meio de uma análise multilingue uma flutuação da percepção pois os limiares de percepção divergem em função dos especialistas. Esta premissa não nos surpreende, pois a percepção auditiva é por natureza extraordinariamente complexa, fugitiva e subjectiva: 
78 OLIVEIRA, Isabelle. Lesitimidade da metáfora em língua de especialidade num quadro didáctico

\begin{tabular}{|l|l|l|}
\hline FRANCÊS & PORTUGUÊS & INGLÊS \\
\hline 1. bruit canon & ruído de canhão & sound of cannon \\
\hline 2. bruit de carillon & ruído de carilhão & $\varnothing^{1}$ \\
\hline 3. froissement de soie & ranger de couro novo & sound of new leather \\
\hline 4. bruit de dactyle & $\varnothing$ & reduplicated second heart sound \\
\hline 5. bruit de diable & sopro vascular & nun's murmur \\
\hline 6. bruit de galop & ruído de galope & gallop rhythm \\
\hline 7. bruit de moulin & ruído hidro-aéreo & sound of a mill \\
\hline 8. bruit de parchemin & $\varnothing$ & sound of parchment \\
\hline 9. bruit de piaulement & $\varnothing$ & sound of whining \\
\hline 10. bruit de pot fêlé & ruído anfórico & crack pot resonance \\
\hline 11. bruit de rappel & $\varnothing$ & sound of a drum beating to arms \\
\hline 12. bruit de rouet & sopro jugular & humming sound \\
\hline 13. bruit de scie & ruído de raspadeira & sound of a saw \\
\hline 14. bruit de sommation & galope de soma & summation sound \\
\hline 15. bruit de soufflet & Sopro & murmur \\
\hline 16. bruit de tambour & $\varnothing$ & sound of drum \\
\hline 17. bruit de trompette & clangor aórtico & $\varnothing$ \\
\hline 18. bruit du triolet & knock pericárdico & mid-systolic click \\
\hline 19. coup de pistolet & tiro de pistola & pistol-shot \\
\hline 20. frémissement cataire & frémito pré- sistólico & purring thrill \\
\hline 21. souffle en écharpe & sopro mitro-aórtico & $\varnothing$ \\
\hline 22. souffle en jet de vapeur & $\varnothing$ & bellow murmur \\
\hline 23. souffle innocent & sopro inocente & innocent murmur \\
\hline 24. souffle losangique & sopro em losango & diamond-shaped murmur \\
\hline 25. souffle tunnelaire & ruído de maquinaria & machinery murmur \\
\hline
\end{tabular}

Deste quadro, depreende-se uma série de observações sobre as quais vamos nos deter alguns instantes. Salienta-se que, frequentemente, o especialista francês não conceptualiza e não denomina o ruído percepcionado da mesma forma de que o seu homólogo português ou inglês. Como explicar este fenómeno? Pela metáfora auditiva utilizada o especialista revela o que entendeu, como a interpretou e como a imaginou, por isso pode-se atribuir este facto a um mero problema de percepção seguido de um problema de ordem cultural. Parece que todas estas representações ou sensações auditivas veiculam uma informação multimodal não linguística baseada na experiência física e cultural do especialista.

1 Sem equivalente. 
Por último, convirá notar que existem também fontes de sensações na língua portuguesa e inglesa que não serão elevadas ao grau de objectos de percepção. Pelos vistos, estes objectos não retêm atenção alguma na cultura científica portuguesa e inglesa pois estão desprovidos de denominação, não houve atribuição de nomes. É assim que ao estabelecer elementos comparativos entre culturas mesmo vizinhas, verifica-se que o que se percepciona numa cultura enquanto objecto identificado não é necessariamente reproduzido noutra cultura.

\section{Conclusão}

O estudo da metáfora em língua de especialidade tem-se revelado, ao longo do tempo, um fenómeno aos contornos complexos onde ainda falta muito por esclarecer. Uma das maiores dificuldades é o facto de ser um fenómeno muito vasto e não ter sido ainda possível abarcá-lo em toda a sua amplidão.

A metáfora funde-se essencialmente numa procura de expressividade para traduzir termos científicos de forma inovadora e acessível ao profano de um domínio especializado. A partir do momento em que a incompreensão se manifesta no seu auditório, o docente recorre a esta "roda de socorro" e guia, desta forma, o aprendente a tecer analogias com a sua experiência quotidiana em vez de escoar o seu pensamento em termos herméticos já adoptados. Evidenciou-se que a metáfora terminológica tece um elo estreito com as experiências assumidas pelos estudantes, isto é, com as suas práxis quotidianas, quer sejam práxis sensori-motoras, culturais, sociais ou linguísticas. Como nota conclusiva, lembremos que a metáfora de especialidade destina-se à lexicalização e à convencionalidade.

\section{Bibliografia}

ALVES, I. M. (2007) Neologismo: criação lexical. 3. ed. São Paulo: Ática.

ASSAL, J-L. (1995) La métaphorisation terminologique. Terminology Update, XXVIII, 2, p. 22-24. DETRIE, C. (2001) Du sens dans le processus métaphorique. Paris: Champion.

DIKI KIDIRI, M. (1996) La métaphore comme base culturelle de conceptualisation et source de néologismes terminologiques. Questions de glottopolitique France, Afrique, Monde méditerranéen. Université de Rouen, Editions Kachouri A., Mallam Garba M.

FONTANIER, P. (1968) Les figures du discours. Paris: Flammarion.

LAKOFF, G.; JOHNSON, M. (1985) Les métaphores dans la vie quotidienne. Paris: Les Editions de Minuit. 
LINO, M. T. (1991) Um projecto em terminodidáctica. Actas do Encontro do Programa ERCI. Lisboa: Universidade Aberta.

OLIVEIRA, I. (2002) Spécificité de la langue de spécialité à partir de la métaphore. Actes de GLAT (Groupe de Linguistique Appliquée des Télécoms). Langues spécialisées et besoins spécifiques: théorie et pratique. Paris, p. 35-46.

(2005) La métaphore terminologique sous un angle cognitif. Méta, Journal des traducteurs, $50, \mathrm{n}^{\circ}$ 4, p. 83-104.

- (2006) La metáfora: estrategia de aprendizaje e sistema de conocimiento. Actes de AETER Comunicar y enseñar a comunicar el conocimiento especializado. Madrid: Instituto Cervantes. p. $149-162$.

. (2006) Pour une approche de la métaphore terminologique. La Banque des Mots, Revue de terminologie française, 72, p. 59-71.

(2006) Base de données en cardiologie. Actes de GLAT (Groupe de Linguistique Appliquée des Télécoms). Aspects méthodologiques pour l'élaboration de lexiques unilingues et multilingues. Bertinoro, p. 29-41.

. (2007) Sens figuré et compréhension humaine. Actes du Colloque interdisciplinaire Nowvelles perspectives de la recherche française sur la langue et la culture portugaise. Clermont-Ferrand, p. 89-98. . (no prelo) Nature et fonctions de la métaphore en science. Paris: L'Harmattan.

THOIRON, Ph.; BEJOINT, H. (eds.) (2000) Le sens en terminologie. Lyon: Presses Universitaires de Lyon.

ABSTRACT: The scope of this paper is to propose a reflection and a contribution about the metaphor in a specialized language, i.e., a kind of metaphor that facilitates, in a context of learning, the transmission of knowledge, the understanding of the abstract to make analogies with the concrete or the familiar. In this regard, we observe how the expert, in the field of cardiology, tries to transmit the knowledge to the students. This, we place the terminological metaphor in a hermeneutic context that implies another way of thinking and another way of seeing the object of description. We must emphasize that in this context, the metaphor operates a re-description of reality. The teacher has at his disposal a highly scientific term or a metaphorical expression to designate the same object. Based on some examples we are going to verify that the metaphorical instrument works as an intralingual translator that essentially assumes the role of illustrator. The specialized metaphor with an explanatory nature stems from a concern of pedagogical clarity and aims at the effectiveness at understanding of abstract concepts. Finally, we focus on the main opportunities and barriers that can be attributed to the metaphor in a context of situation of learning.

KEYWORDS: Terminological metaphor; metalanguage; learning; social stratification. 